Relato de experiência

\title{
Prova escrita em aulas remotas: uma experiência no oitavo ano
}

\author{
Written test in remote classes: an experience in the eighth grade
}

Prueba escrita en clases remotas: una experiencia en el octavo grado

\author{
Milene Aparecida Malaquias Cardoso ${ }^{1}$ \\ (i) [0000-0002-2918-3731] \\ Regina Luzia Corio de Buriasco ${ }^{2}$ \\ [0000-0002-5845-1619]
}

\section{Resumo}

Este artigo apresenta o relato da aplicação de uma prova escrita de matemática para vinte alunos de uma turma de 80 ano do Ensino Fundamental, durante aulas remotas. As resoluções escritas dos alunos foram analisadas e os resultados mostram que, durante a aplicação dessa prova escrita, nas condições aqui relatadas, os alunos se pronunciaram mais, com questionamentos ao professor sobre as questões da prova. Partindo do interesse dos alunos, esse foi o momento em que mais se falou a respeito do conteúdo. Essa experiência mostrou que a avaliação pode ser mais uma oportunidade de aprendizagem.

Palavras-chave: Educação Matemática. Avaliação da Aprendizagem. Análise da Produção Escrita. Prova Escrita.

\section{Abstract}

This article presents the report of the application of a written math test to twenty students of 8th grade elementary school class, during remote classes. The students' written resolutions were analyzed and the results show that, during the application of this written test, under the conditions reported here, the students spoke more, asking the teacher about the test questions. Based on the interest of the students, this was the moment when the content was most talked about. This experience showed that assessment can be another learning opportunity.

Keywords: Mathematics Education. Learning Assessment. Written Production Analysis. Written Test.

\section{Resumen}

Este artículo presenta el informe de la aplicación de una prueba escrita de matemáticas a veinte alumnos de una clase de 8 o grado de primaria, durante clases remotas. Se analizaron las resoluciones escritas de los estudiantes y los resultados muestran que, durante la aplicación de esta prueba escrita, en las condiciones aquí reportadas, los estudiantes hablaron más con el docente sobre las preguntas de la prueba. A partir del interés de los alumnos, este fue el momento en el que más se habló del contenido. Esta experiencia demostró que la evaluación puede ser otra oportunidad de aprendizaje.

Palabras clave: Educación Matemática. Evaluación del aprendizaje. Análisis de la producción escrita. Prueba escrita.

${ }^{1}$ milenecmatematica@gmail.com, professora da Educação Básica, mestre em Ensino de Matemática pela Universidade Tecnológica Federal do Paraná (UTFPR/Londrina) e doutoranda em Ensino de Ciências e Educação Matemática pela Universidade Estadual de Londrina (UEL)/ Londrina/ Paraná/ Brasil.

${ }^{2}$ reginaburiasco@gmail.com, doutora em Educação Matemática pela Universidade Estadual Paulista Júlio de Mesquita Filho (UNESP), docente do Programa de Pós-Graduação em Ensino de Ciências e Educação Matemática da Universidade Estadual de Londrina (UEL)/ Londrina/ Paraná/ Brasil. 


\section{Introdução}

Mesmo com a existência de vários instrumentos de avaliação, a prova escrita ainda é um dos instrumentos mais utilizados nas escolas da Educação Básica para avaliar a aprendizagem dos alunos (FERREIRA, 2009), e, muitas vezes, o único. Tal prática parece mostrar que os professores consideram avaliação como sinônimo de prova escrita.

Nesse caso, para diagnosticar o aprendizado e criar oportunidades diversas para os alunos expressarem seus conhecimentos, é desejável que o professor, ao corrigir uma prova escrita, não considere apenas o resultado como correto ou incorreto, sem analisar o que o aluno fez, pensou, ou como chegou àquele resultado. A análise da produção escrita do aluno pode possibilitar ao professor diferentes tomadas de decisões em suas escolhas didáticas (SANTOS, 2014).

Em 2020, as atividades escolares tiveram início no dia 2 de fevereiro e tudo transcorria normalmente até a semana do dia 16 de março de 2020. Em decorrência do Decreto $n^{\circ} .4230$, as atividades escolares presenciais foram encerradas como forma de reduzir o contato entre as pessoas para conter a propagação do novo coronavírus e evitar a COVID-193. Assim, o planejamento escolar teve que ser reestruturado, sendo a avaliação um dos seus itens de maior importância a ser repensado.

Nesse contexto, este trabalho tem o objetivo de relatar a aplicação e a análise da produção de alunos em uma prova escrita de matemática, cujo conteúdo era juros simples e compostos. A prova escrita foi aplicada, via aula remota ${ }^{4}$ a vinte alunos de uma turma do 8 . ano do Ensino Fundamental de uma escola particular em uma cidade no norte do Paraná, durante o isolamento social. Algumas reflexões sobre avaliação da aprendizagem e uma análise da produção escrita foram inicialmente apresentadas.

\section{Avaliação da aprendizagem e análise da produção escrita}

A avaliação escolar, na perspectiva aqui adotada, objetiva ser uma oportunidade de aprendizagem para o aluno, buscando seu desenvolvimento durante um certo período, não necessitando, assim, ela mesma, da apresentação de nota.

Segundo Hadji (1994), tradicionalmente, existem três tipos de avaliações no decorrer dos processos de ensino e de aprendizagem. A somativa, que ocorre depois da ação de formação e visa classificar, situar, informar o aluno. A diagnóstica, que ocorre antes da ação de formação e tem função orientadora. A formativa, que ocorre durante a ação de formação e tem como principal função regular os processos de ensino e de aprendizagem, contribuindo para a formação dos envolvidos.

Assim, em educação, a avaliação é um processo pelo qual informações são recolhidas e disponibilizadas, para subsidiar possíveis decisões para o trabalho pedagógico. Na obtenção dessas informações, podem ser utilizados diversos tipos de instrumentos e a prova escrita se

\footnotetext{
${ }^{3}$ A COVID-19 é uma doença causada pelo novo coronavírus, denominado SARS-CoV-2. Ela apresenta um espectro clínico variando de infecções assintomáticas a quadros graves. De acordo com a Organização Mundial de Saúde, a maioria (cerca de $80 \%$ ) dos pacientes com COVID-19 pode ser assintomática ou oligossintomática (com poucos sintomas), enquanto aproximadamente $20 \%$ dos casos detectados requerem atendimento hospitalar por apresentar dificuldade respiratória; desses, aproximadamente $5 \%$ podem necessitar de suporte ventilatório. (https://coronavirus.saude.gov.br/sobre-a-doenca\#o-que-e-covid)
}

${ }^{4}$ Aulas ao vivo, por meio de aplicativo de internet. 
destaca como um dos mais utilizados. Ao resolver questões abertas ou discursivas, o aluno produz registros escritos que revelam, entre outras, a forma como interpretou a questão, as estratégias e procedimentos que escolheu, conteúdos matemáticos utilizados que, em processo de aprendizagem, são informações importantes que merecem a atenção do professor no momento de avaliação.

Segundo Buriasco (2004), a produção escrita dos alunos é uma rica fonte para entender os processos de ensino e de aprendizagem, bem com os procedimentos e as estratégias utilizados por eles para resolver problemas.

Quando se faz uma análise da produção escrita dos alunos, essa análise ajuda o professor a refletir sobre seu planejamento, no desenvolvimento e na avaliação da sua prática pedagógica. Assim, a avaliação da aprendizagem dos alunos pode ser considerada "como um questionar sobre o sentido do que é produzido na situação observada." (HADJI, 1994, p. 71).

A análise da produção escrita dos alunos é relevante, seja ela obtida por meio de trabalhos, de provas ou de quaisquer outros instrumentos que possibilitem o registro de ideias.

Nessa perspectiva a análise da produção escrita em matemática, considerada como um conjunto de ações frente à produção escrita do aluno que fornece ao professor informações sobre o que ele mostra saber ou não. Com isso, configura-se como uma estratégia de avaliação.

\section{Relato e análise da experiência}

Nesta experiência, investigamos como professor e aluno lidam com uma prova escrita de matemática aplicada em aulas remotas, que ocorreu nas aulas ministradas pela primeira autora deste artigo em um período de isolamento social, em uma turma de vinte alunos do 8‥ ano do Ensino Fundamental, de uma escola privada de uma cidade do interior do estado do Paraná. Nessa escola, o sistema de avalição ${ }^{5}$ é composto por uma prova escrita ao final de cada trimestre, contendo dez questões, e mais algumas provas contendo questões objetivas que são aplicadas semanalmente.

Na semana de 16 de março de 2020, as atividades escolares presenciais foram encerradas em decorrência do Decreto $n^{\circ} .4230$, como forma de reduzir o contato entre as pessoas para conter a propagação do novo coronavírus e evitar a COVID-19. Diante desse isolamento social, a escola, a coordenação e os professores tiveram que pensar no que fazer para manter o contato com os alunos em relação às aulas, ainda que a distância. Na semana seguinte, os professores começaram a gravar pequenos vídeos em casa com conteúdo de revisão para mandar aos alunos. Nessa fase, a coordenação da escola orientou a não incluir conteúdo novo para não prejudicar os alunos. Todavia, nem todos os professores da escola dispunham de ferramentas e recursos para gravar seu próprio vídeo. Assim, a coordenação resolveu que os professores gravariam suas aulas em um estúdio feito no prédio da escola, com horário agendado. Ao término de cada aula, os equipamentos seriam higienizados para evitar qualquer contaminação. As aulas deviam ser preparadas com uma duração de 8 a 10 minutos cada uma, com conteúdos novos ou não, podendo utilizar recursos disponibilizados pela escola, como quadro e giz, projetor e tablet.

\footnotetext{
${ }^{5}$ Em um ano "normal", ou seja, com aulas presenciais, com a pandemia no primeiro trimestre os alunos fizeram uma prova escrita de cada uma das disciplinas.
} 
Diante disso, os professores precisaram aprender a lidar com várias ferramentas tecnológicas em menos de uma semana. Esse lidar causou estranhamentos, angústias, desafios e medos, uma vez que não estavam preparados para todas essas mudanças ao mesmo tempo. O que ajudou a superar alguns obstáculos foi o contato uns com os outros pelos grupos de WhatsApp. Apesar do isolamento social, os professores nunca estiveram tão próximos, nunca houve tanta empatia.

As aulas foram gravadas no prédio da escola entre os dias 3 e 7 de abril de 2020 . Durante essa semana de gravação, a coordenação decidiu antecipar o recesso escolar do mês de julho para diminuir a perda de dias letivos. Na semana seguinte, a partir do dia 13 de abril, as aulas foram disponibilizadas aos alunos pela conta da escola no YouTube. Para que essas aulas fossem juridicamente validadas para os alunos, cada professor foi orientado pela coordenação a enviar-lhes, por meio do Clip Escola ${ }^{6}$, uma tarefa sobre o conteúdo explicado nas aulas gravadas e instruí-los a entregar as tarefas quando retornassem às aulas presenciais.

Na mesma semana, a coordenação da escola solicitou que os alunos conhecessem o Zoom Reuniões, um aplicativo que permite realizar reuniões pelo celular ou pelo computador, pois, já na semana seguinte ele seria utilizado para as aulas remotas, o que de fato ocorreu (semana de 20 de abril). Nas aulas com os 80 s. anos, foi então iniciado o trabalho com o tema juros compostos, dando continuidade às aulas no material apostilado, uma vez que as aulas gravadas continham diferentes representações da porcentagem, aumentos e descontos percentuais, aumentos e descontos sucessivos e juros simples. As aulas foram preparadas em slides pelo Power Point, que eram compartilhados com os alunos no momento da aula para a explicação ou correção das tarefas. Para escrever nos slides, foi necessário adquirir uma mesa digitalizadora. Isso facilitou muito as aulas remotas, já que todas requeriam escrita como é feita no quadro, o que não seria possível apenas com o mouse. As aulas remotas foram uma surpresa, pois houve $100 \%$ de presença dos alunos. Suas câmeras ficavam ligadas, pois a coordenação entrava nas salas para fazer a chamada de presença, e quem não estivesse com a câmera ligada receberia falta, a não ser que o aluno tivesse algum problema técnico.

No dia 29 de abril, a escola comunicou que, no dia seguinte, haveria uma reunião para fazer um feedback das aulas remotas. Nessa reunião, foi informado que os alunos deveriam ser avaliados, ou seja, precisava-se de uma nota. Para isso, foi sugerido que se elaborasse uma prova escrita em slides e, que, durante as aulas remotas, fossem expostos um a um. Assim, eles resolveriam as questões em uma folha de sulfite para entregar posteriormente.

Essa prova escrita deveria ter, no máximo, dez questões, podendo conter questões discursivas ou objetivas e começar com um cabeçalho para a identificação dos alunos. Seu valor era de cem pontos, pois, naquele momento, seria o único instrumento a ser utilizado para avaliar os alunos. Para a aplicação, o professor poderia utilizar quantas aulas fossem necessárias, durante a semana de provas. Além disso, a coordenação orientou que, durante a aplicação da prova escrita, deveriam ser tiradas as dúvidas dos alunos em relação às questões propostas.

Com as orientações dadas pela coordenação, elaborou-se uma prova escrita-composta por cinco questões que versavam sobre o tema juros simples e juros compostos. No momento da elaboração da prova escrita, pensou-se em colocar questões que haviam sido trabalhadas com maior intensidade e que fossem semelhantes às tarefas desenvolvidas nas aulas remotas. Ou seja, foram colocadas questões que demandavam reprodução, exigindo apenas aplicação

${ }^{6}$ Clip Escola é um aplicativo usado para tarefas, recados e orientações para os pais e alunos. 
de algoritmos simples e conhecidos e realizar procedimentos rotineiros. O objetivo era saber se os alunos conseguiriam utilizar o algoritmo apropriado e calcular os juros simples e juros compostos em uma tarefa como as que haviam sido feitas durante as aulas. A Figura 1 ilustra como a prova escrita foi proposta aos alunos.

Figura 1 - Prova proposta para os alunos.

\section{PROVA DE MATEMÁTICA}

1. Depositando R\$่ 900,00 em uma aplicação que rende $2 \%$ ao mês a juros compostos, que montante terá após 4 meses? Complete a tabela e descubra!

\begin{tabular}{|l|l|l|l|}
\hline Tempo & Capital (em reais) & Juros (em reais) & Montante (em reais) \\
\hline Após 1 mês & & & \\
\hline Após 2 meses & & & \\
\hline Após 3 meses & & & \\
\hline Após 4 meses & & & \\
\hline
\end{tabular}

- Quantos reais renderá essa aplicação?

2. Uma pessoa fez um empréstimo de $\mathrm{R} \$ \mathbf{8 0 0 , 0 0}$ e vai pagar $3 \%$ ao mês a juros simples.

a) Qual é o total de juros que ela pagará por esse empréstimo após 3 meses?

b) Quanto ela deverá pagar pelo empréstimo após 3 meses?

3. Determine o montante de uma aplicação de $\mathbf{R}$ 5.000,00 à taxa de 1,3\% ao mês durante 4 meses:

a) a juros simples;

b) a juros compostos.

4. (ENEM) João deseja comprar um carro cujo preço à vista, com todos os descontos possíveis, é de $\mathbf{R S ̧} 21.000,00$, e esse valor não será reajustado nos próximos meses.

Ele tem R\$ $20.000,00$, que podem ser aplicados a uma taxa de juros compostos de $2 \%$ ao mês, e escolhe deixar todo o seu dinheiro aplicado até que o montante atinja o valor do carro.

Para ter o carro, João deverá esperar:

a) dois meses, e terá a quantia exata.

b) três meses, e terá a quantia exata.

c) três meses, e ainda sobrarão, aproximadamente, $\mathrm{R} \$ \mathbf{2 2 5 , 0 0 .}$

d) quatro meses, e terá a quantia exata.

e) quatro meses, e ainda sobrarão, aproximadamente, $\mathrm{R} \$ \mathbf{4 3 0 , 0 0}$.

5. Luciana resolveu aplicar RȘ $\mathbf{1 2 . 0 0 0 , 0 0 ~ e m ~ u m ~ f u n d o ~ d e ~ i n v e s t i m e n t o , ~ c u j a ~ t a x a ~ d e ~ j u r o s ~}$ compostos é mensal. Se ao final do primeiro mês o montante foi de R\$̣ 12.144,00, determine:

a) a taxa de juros mensal dessa aplicação;

b) o montante após 3 meses de aplicação.

Fonte: elaborada pela primeira autora. 
No início de maio, os alunos tiveram três aulas remotas de 40 minutos cada uma, em três dias distintos, para a resolução da prova escrita. Além das aulas, eles também poderiam tirar fotos dos slides com as questões da prova escrita para resolvê-las fora do horário das aulas remotas. Foi combinado com os alunos que poderiam utilizar, como material de apoio, o caderno, a apostila e a calculadora. Além disso, se julgassem necessário, poderiam se comunicar uns com os outros e pesquisar na Internet. Assim, tinham vários recursos para auxiliá-los a responder a prova escrita. Durante a exposição de cada um dos slides, os alunos poderiam fazer perguntas, para o professor, relacionadas às questões propostas, mas não lhes seria dito se a resposta estava correta ou não. Mantendo o isolamento social, no início do mês de julho, a coordenação da escola solicitou aos pais e alunos que entregassem a prova escrita no prédio da escola para que se pudesse fazer a correção.

Por limitações de espaço, não será possível relatar neste artigo todas as respostas dos alunos. Então, decidiu-se apresentar, de modo geral, o que os alunos responderam em cada uma das questões da Figura 1, enfatizando o modo de lidar com elas mesmo com o auxílio da professora. Uma suspeita era a de que, com todos os recursos disponíveis aos alunos, suas resoluções da prova escrita estariam mais próximas das consideradas corretas, ou que as resoluções estariam semelhantes entre si, já que eles poderiam, inclusive, copiar um do outro. Entretanto, como se verá, os alunos apresentaram resoluções distintas, algumas das quais consideradas incorretas.

Na questão número 1, quinze alunos acertaram os cálculos ao completar a tabela, porém apenas sete deram a resposta considerada correta em relação à pergunta "Quantos reais renderá essa aplicação?". Três alunos colocaram como resposta o montante de R\$ 974,19 , o valor esperado era $\mathrm{R} \$ \mathbf{7 4 , 1 9}$. Acredita-se que consideraram esse valor como correto por ser o último número a completar a tabela. Três alunos não apresentaram resposta a essa pergunta. Com relação a isso, talvez os alunos tenham acreditado que, ao completar a tabela, já estavam respondendo, ou não atentaram para essa pergunta. $\mathrm{O}$ aluno $8 \mathrm{E} 3^{7}$ (Figura 2) apresentou como resposta a diferença entre os dois últimos montantes calculados por ele: "R\$974,18 - R\$955,08". Ele fez o cálculo da subtração corretamente, porém com valores que não responderam à questão proposta. A leitura em relação a essa resolução é que o aluno 8E3 pode não ter entendido a relação entre o montante, o capital inicial e os juros (rendimento).

Figura 2 - Resolução do aluno 8E3 da questão 1.

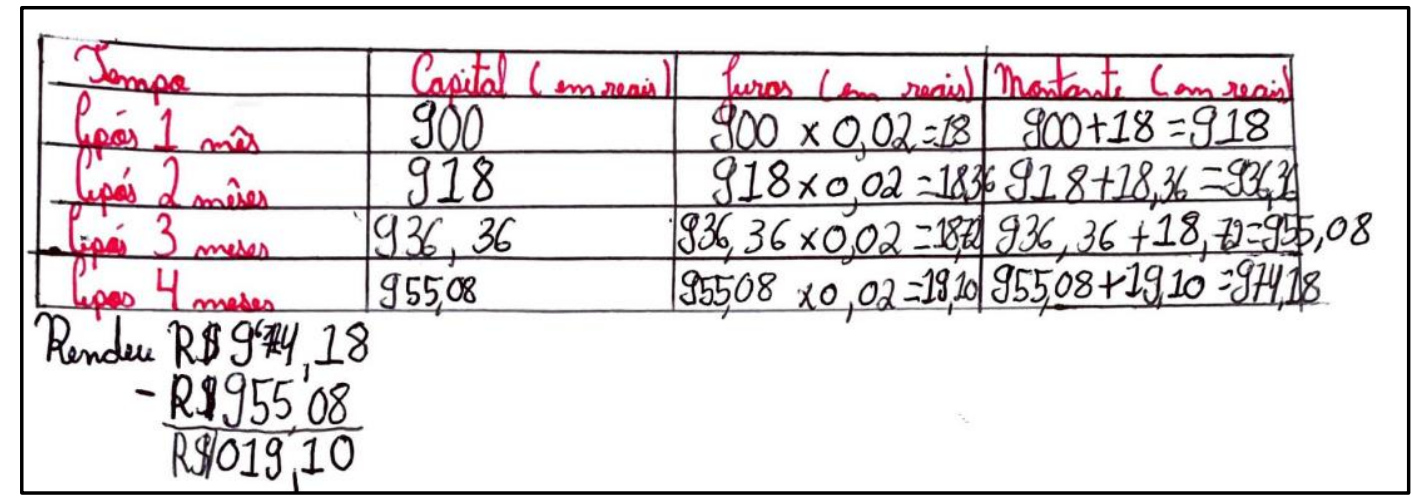

Fonte: Prova de 8E3.

\footnotetext{
${ }^{7}$ As produções foram identificadas com 3 ou 4 itens (números e letras). O primeiro número refere-se a série/ano, o segundo item (letra) refere-se à turma, e o terceiro item (número) refere-se ao aluno. Em alguns casos, há um quarto item (A ou $B)$, que se refere à frente ou ao verso da prova escrita.
} 
Ainda a respeito da questão número 1 , cinco alunos não conseguiram chegar à resposta considerada correta; destes, são apresentadas duas resoluções. O aluno 8E20 (Figura 3) apresentou apenas os montantes de cada uma das linhas da tabela, porém, no montante da quarta linha em vez de escrever $\mathrm{R} \$ 955,08$, valor esperado do montante da quarta linha, escreveu $\mathrm{R} \$ 55,08$. Além disso, ele não deu a resposta do montante da última linha, nem apresentou resposta à pergunta: "Quantos reais renderá essa aplicação?". Ao analisar a produção escrita desse aluno, a impressão era de ele ter perdido a prova escrita com resolução feita junto com a professora e os colegas durante a aplicação da prova no mês de maio, já que foi sugerido que fizessem a construção da tabela para não se perderem. Além disso, durante a aplicação da prova escrita, os alunos tiveram vários questionamentos a respeito de como resolver essa questão, e a professora foi fazendo passo a passo para ajudá-los. Uma outra possibilidade é que ele quisesse entregar dessa maneira, uma vez que a escolha do que fazer ou não é de quem resolve a prova.

Figura 3 - Resolução do aluno 8E20 da questão 1.

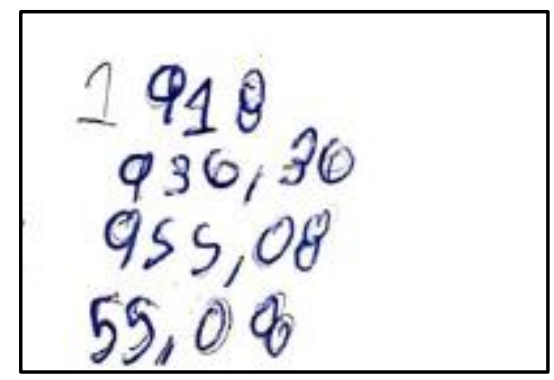

Fonte: Prova de 8E20.

Outra resolução que chamou a atenção foi a do aluno 8E2. Ele não conseguiu chegar à resposta considerada correta para a questão número 1 , pois apresentou equívocos quanto à posição das vírgulas. No momento da aplicação da prova, surgiram várias dúvidas quanto onde posicionar a vírgula, ou se em lugar da vírgula deveriam utilizar ponto. Essa dúvida surgiu porque alguns resultados entre eles não saíam iguais. Perguntando aos alunos, tentou-se investigar como eles estavam fazendo os cálculos. Percebeu-se que, mesmo utilizando a calculadora, eles estavam com dúvida quanto à posição da vírgula. Para sanar essa dificuldade, é usual o professor resolver vários exercícios do mesmo tipo na lousa, acreditando que o aluno aprenderá com isso, porém essa estratégia não funcionou. Ao analisar as provas escritas, pôde-se perceber que alguns dos alunos demostraram continuar com a mesma dificuldade, como pode ser observado na Figura 4. Ao analisar a resolução do aluno 8E2, a leitura foi que, ele, ao calcular os juros do segundo mês, não colocou a vírgula no $\mathrm{R} \$ 18,36$. Isso pode ter acontecido por ele usar a calculadora do celular, ou por acreditar que $\mathrm{R} \$ 18,36$ é um valor pequeno perto de $\mathrm{R} \$ 918,00$. Na mesma linha relativo ao segundo mês, o aluno 8E2 fez o cálculo do montante de $\mathrm{R} \$ 918+\mathrm{R} \$ 1836=9.363$. Esse resultado intrigou, pois não se conseguiu inferir como ele chegou a 9.363. Uma suspeita com relação à resolução desse aluno é que, para ele, o ponto é usado com vários algarismos diferentes de zero (18.7272), e a vírgula, para números com poucos algarismos, como o 0,02. Fica evidente que esse item deve ser retomado pela professora em aulas futuras, já que $8 \mathrm{E} 2$ e outros alunos apresentaram respostas consideradas incorretas quanto ao posicionamento e uso da vírgula. 
Figura 4 - Resolução do aluno 8E2 da questão 1.

\begin{tabular}{|c|c|c|c|c|}
\hline $1 \rightarrow$ & TEMPO & CAP.(EM REA IS) & JUROS (EM REAIS) & MONTANTE (EM REAIS) \\
\hline & após 1 mîs & 900 & $900 \times 0,02=18$ & $900+18=918$ \\
\hline & após 2 meses & 918 & $918 \times 0,02=1836$ & $918+1836=9.363$ \\
\hline & após 3 meses & 9.363 & $\begin{array}{c}9363 \times 0,02 \\
=18.7272\end{array}$ & $9363+18.727=28.09$ \\
\hline & apés 4 muses & 28.09 & $\begin{array}{l}2809 \times 0,02= \\
5618\end{array}$ & $2809+5618=8427$ \\
\hline
\end{tabular}

Fonte: Prova de 8E2.

Em relação à questão 2, dezesseis alunos conseguiram chegar às respostas consideradas corretas, e quatro alunos não conseguiram. Dentre esses quatro, duas resoluções chamaram a atenção, a do aluno 8E2 (Figura5) e a do aluno 8E8A (Figura 6).

Figura 5 - Resolução do aluno 8E2 da questão 2.

$2 \rightarrow$ a) J.c.i.t $\quad J=8.0,03 \cdot 3 \quad$ b) $m=C+J=872$
$J=0,72$

Fonte: prova de 8E2.

Durante a aplicação da prova escrita, os alunos perguntavam do modo de resolver as questões. Assim, na tentativa de ajudá-los, incentivava-se a buscar resoluções semelhantes nas tarefas de sala de aula, além de dar explicações quando necessário. Durante a resolução da questão 2, foi retomado o modo de resolver uma questão com juros simples. Os alunos encontraram tarefas semelhantes à questão na apostila, no entanto, notou-se, na resolução do aluno 8E2, um engano ao escrever a fórmula dos juros simples. $\mathrm{O}$ aluno escreveu "juros vezes capital vezes a taxa vezes o tempo", mesmo considerando dessa maneira, ele realiza esse cálculo corretamente. É possível que ele tenha se enganado ao escrever a fórmula. Apesar de ter retirado os dados corretamente, quando substituiu o capital inicial de $\mathrm{R} \$ 800$, utilizou o 8. A esse respeito, a leitura é que, ao escrever a taxa de juros em número decimal, quando o aluno deve dividir por 100 , ele pode ter feito o mesmo com o capital inicial.

Figura 6 - Resolução do aluno 8E8A da questão 2.

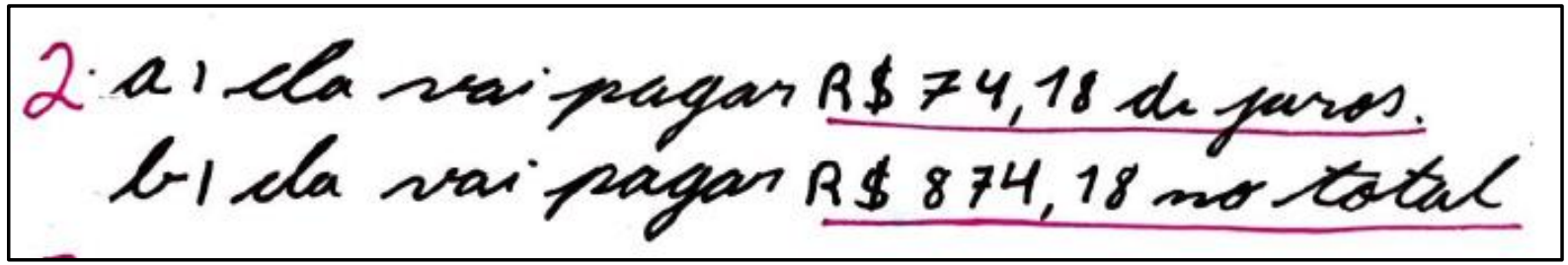

Fonte: Prova de 8E8A. 
Na resolução do aluno 8E8A, observou-se que a resposta que ele deu ao item da questão é igual à resposta da pergunta "Quantos reais renderá essa aplicação?", da questão número 1 , e a resposta do item $b$ também é semelhante ao montante da última linha da tabela da questão número 1. Acredita-se que o aluno tenha se confundido com os resultados. Como ele não demonstrou os cálculos, ou seja, ele apresenta apenas a resposta final, não se consegue fazer uma inferência a respeito de como ele chegou aos resultados apresentados.

Quanto à questão 3, oito alunos acertaram totalmente a questão, cinco alunos acertaram apenas o item a da questão, e sete alunos erraram totalmente a questão. Pelas resoluções apresentadas pelos alunos, percebe-se que a maioria deles acertou a questão, quando se tratava de calcular os juros simples, com o que se acredita que tenham maior facilidade. Outra inferência que se pode fazer é a de que o cálculo de juros compostos demanda um número maior de procedimentos a serem desenvolvidos.

Dos alunos que não conseguiram apresentar uma resposta considerada correta para a questão 3, chamou a atenção a resolução do aluno 8E5A. Ele "montou" corretamente a conta, fez os cálculos corretos dos juros simples, mas apresentou valor de $\mathrm{R} \$ 260.000$. Em vez de utilizar a vírgula, usou o ponto no número $\mathrm{R} \$ 260.000$. Assim, infere-se que ele não conseguiu entender a diferença entre a utilização de um ponto e de uma vírgula, fazendo a interpretação de que o número ficou cem mil vezes maior. Ao adicionar o capital inicial de $\mathrm{R} \$ 5000$, encontrou o valor de $\mathrm{R} \$ 265.000$. Aqui a dificuldade é entre usar o ponto ou a vírgula, o que mostra grande parte das resoluções apresentadas pelos alunos.

Figura 7 - Resolução do aluno 8E5A da questão 3.

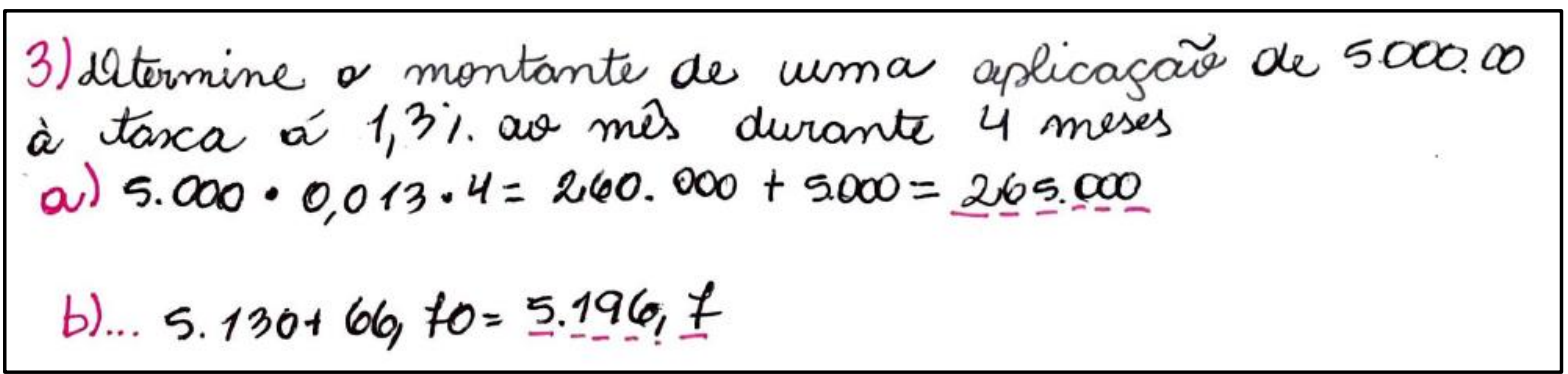

Fonte: Prova de 8E5A.

Havia uma suspeita de que, na questão 4, por ser de múltipla escolha, a maioria dos alunos apenas assinalaria a resposta correta sem apresentar a resolução, porém não foi o que ocorreu. Quinze alunos responderam corretamente à questão; desses, onze apresentaram uma resolução e quatro colocaram a alternativa correta. Pode-se pensar, em relação a essa situação, que, quando o aluno dispõe de recursos e mais tempo para lidar com as questões da prova escrita, ele pode querer mostrar mais o que sabe.

Em relação à questão 5 , sete alunos resolveram a questão da maneira considerada correta, dez apresentaram resoluções consideradas incorretas e três não responderam à questão. Os dez alunos que apresentaram resoluções incorretas erraram ao responder ao item a, ou seja, encontrar a taxa de juros. Considerando todas as questões da prova escrita, essa foi a que apresentou o maior índice de resoluções incorretas. Uma inferência com relação a isso é que, por se tratar de uma questão em que o aluno teria que encontrar a taxa de juros, e não apenas os juros, algo que é mais habitual. Ainda assim, o auxílio da professora e as tarefas realizadas em sala de aula não foram suficientes para que eles conseguissem resolvêla. 
Em relação ao aluno 8E9B, a leitura é que ele, em sua resolução, retirou os dados corretamente e escolheu uma estratégia que resolveu, também corretamente, a questão. Enganou-se, porém, ao fazer a divisão de 12000 por 144, o capital inicial pelos juros, em lugar de fazer os juros pelo capital inicial. A maioria dos alunos teve o mesmo erro. Acredita-se que os alunos estão habituados a fazer divisão em que o dividendo é maior que o divisor; quando o contrário acontece, eles ficam vulneráveis a erros.

Figura 8 - Resolução do aluno 8E9B da questão 5.

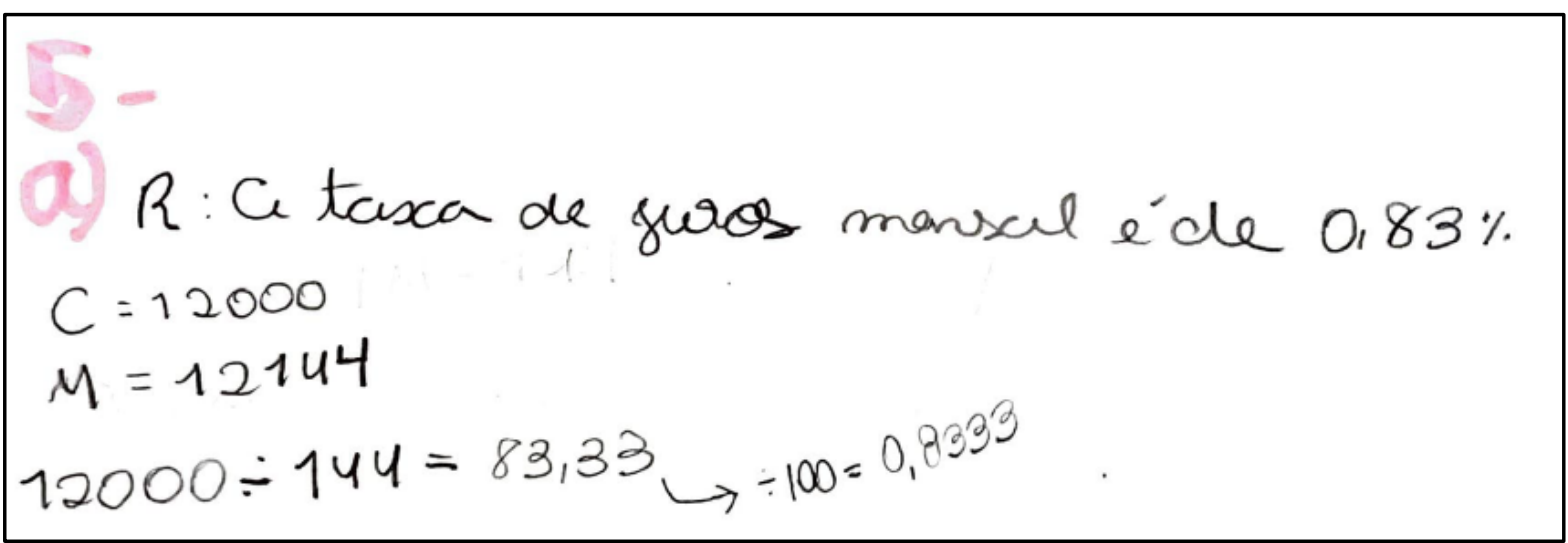

Fonte: Prova de 8E9B.

Durante a aplicação da prova escrita, ficou evidente pelos questionamentos feitos pelos alunos que, mesmo com as questões da prova sendo semelhantes às tarefas realizadas em sala de aula, os alunos ainda apresentaram dificuldades na execução das questões. Isso mostra que ter apenas questões de reprodução em uma prova escrita não garante o sucesso dos alunos.

\section{Algumas considerações}

Neste artigo, relatou-se uma experiência um tanto quanto incomum nas aulas de matemática: aplicar uma prova escrita em aulas remotas com recursos disponíveis para sua resolução. Com isso, suspeitava-se que todos iriam tirar nota máxima ou que os cálculos e as respostas seriam semelhantes. Como se viu, porém, depois da aplicação e da análise da produção escrita dos alunos, não foi isso que aconteceu, pois só conseguiam fazer algumas questões se a professora fizesse quase todos os procedimentos.

Durante a aplicação da prova escrita, os alunos se mostraram interessados no conteúdo abordado e levantaram vários questionamentos. Insistiram com a professora a fim de compreenderem as questões da prova escrita. Foi o momento em que a professora mais falou a respeito do conteúdo, partindo do interesse dos alunos. Tantos questionamentos levantaram a suspeita de que talvez os alunos tivessem se preparado para a resolução dessa prova escrita, uma vez que eles sabiam que teriam todos os recursos disponíveis.

Apesar da disponibilidade de recursos para a resolução da prova escrita, notou-se que os alunos não os utilizaram tanto quanto esperado, uma vez que, durante as análises, foram encontradas resoluções consideradas incorretas. Pensou-se, então, que era porque os alunos não estavam habituados a esse tipo de situação, em que poderiam consultar outras fontes. Acredita-se que o recurso mais utilizado pelos alunos foi o professor, mostrando uma certa dependência da figura do professor. 
Ficou claro, com esta experiência, que diferentes estratégias no processo de avaliação podem ajudar tanto professor quanto aluno nos processos de ensino e de aprendizagem. A avaliação como mais uma oportunidade de aprendizagem.

\section{Referências}

BURIASCO, Regina. L. C. de. Análise da Produção Escrita: a busca do conhecimento escondido. In: XII ENDIPE - Encontro Nacional de Didática e Prática de Ensino, 2004, v.3, Curitiba. Anais... Curitiba: Champagnat, 2004. p. 243-251.

FERREIRA, Pamela. E. A. Análise da produção escrita de professores da Educação Básica em questões não rotineiras de matemática. 2009, 166f. Dissertação (Programa de Pós- Graduação em Ensino de Ciências e Educação Matemática) - Universidade Estadual de Londrina, Londrina, 2009.

HADJI, Charles. A avaliação, regras do jogo das intenções aos instrumentos (4.ed.). Portugal: Porto Editora, 1994.

SANTOS, Edilaine R. dos. Análise da produção escrita em matemática: de estratégia de avaliação a estratégia de ensino. 2014, 108f. Dissertação (Mestrado em ensino de Ciências e Educação Matemática) - Centro de Ciências Exatas, Universidade Estadual de Londrina, 2014. 